\title{
Huge mucinous borderline ovarian cystadenoma in a premenarchal girl
}

\author{
Atsushi Horiuchi, Kazuhiro Kameoka, Kouichi Sato, Yuji Yamamoto, Yuji Watanabe \\ Department of Surgery, Division of Gastrointestinal Surgery and Surgical Oncology, School of Medicine, Ehime University, Toon \\ City, Japan \\ Email: atsushi@m.ehime-u.ac.jp
}

Received 30 August 2011; revised 2 December 2011; accepted 16 January 2012

\begin{abstract}
Epithelial ovarian tumors are common in adult women, but rare in children. Especially mucinous ovarian cystadenoma is extremely rare, with only 16 cases in premenarchal girls reported to date. We present a case of 12-year-old premenarchal girl with symptoms of lower abdominal distension. CT showed a large multilocular tumor spreading throughout the entire abdominal cavity from the right upper quadrant to the pelvic cavity. The tumor was brought out little by little with aspiration of the fluid contents with a small incision. The tumor was found to originate from the left ovary, and oophorectomy was performed. The tumor measured $26 \times 18 \mathrm{~cm}$ and weighed $5860 \mathrm{~g}$. Histological diagnosis was mucinous ovarian cystadenoma with borderline malignancy. No evidence of recurrence had been seen as of 2 years postoperatively. In the review of premenarchal mucinous borderline ovarian cystadenoma, all cases were stage I and underwent salpingo-oophorectomy or oophorectomy. Those patients were alive without recurrence. Although mucinous borderline ovarian cystadenoma was characterized as malignancy, premenarchal cases showed favorable outcomes and salpingo-oohprectomy or oophorectomy appears appropriate.
\end{abstract}

Keywords: Ovary; Mucinous Cystadenoma; Borderline Tumor; Premenarchal

\section{INTRODUCTION}

It has been reported that $40 \%-50 \%$ of childhood ovarian masses are nonneopalastic, and the majority of ovarian neoplasms in children arise from germ cells [1,2]. A small proportion of ovarian tumors in children (approximately $15 \%-20 \%$ ) is derived from the ovarian epithelium. Such epithelial ovarian tumors are commonly found in adults, but these tumors, including serous and mucinous types, are extremely rare in premenarchal girls [3-5]. Each mucinous ovarian tumor can be further char- acterized as benign, malignant, or of low malignant potential, with this latter group recognized as borderline tumors [6]. We present herein the case of a mucinous borderline ovarian cystadenoma in a 12-year-old premenarchal girl, and reviewed the cases of mucinous ovarian tumors in premenarchal girls reported in the medical literature.

\section{CASE REPORT}

A 12-year-old premenarchal girl noticed lower abdominal distention about 1 year prior to presentation. She sometimes experienced abdominal pain and constipation, but disregarded those symptoms as not severe enough to prevent the activities of daily life. She consulted a nearby clinic after increasing abdominal distention was detected by her family. She was referred to our hospital after identification of the abdominal tumor by that clinic. Abdominal contrast-enhanced computed tomography (CT) showed a large multilocular tumor with clear boundaries spreading throughout the entire abdominal cavity from the right upper quadrant to the pelvic cavity (Figure 1). The maximum diameter of each cyst was around $15 \mathrm{~cm}$. Cyst contents were homogenous and cyst walls were not enhanced. The tumor compressed the whole bowel and uterus to the left. On magnetic resonance imaging (MRI) lesions showed high intensity on T1-weighted imaging and low intensity on T2-weighted imaging (Figure 2). Carbohydrate antigen 125 (CA125) level was 45.5 IU/l, showing a slight elevation, but the other tumor markers were with normal ranges.

The patient underwent laparotomy with a small lower abdominal incision, as preoperative findings suggested poor malignant potential of the tumor. The tumor was brought out little by little with aspiration of the fluid contents from inside the tumor, which amounted to 4280 $\mathrm{ml}$ of serous yellow fluid. Prevention of fluid spillage was then taken into consideration. The tumor was found to originate from the left ovary, independent of surrounding organs and with no adhesion to the small intestine or colon. The patient underwent left oophorectomy 


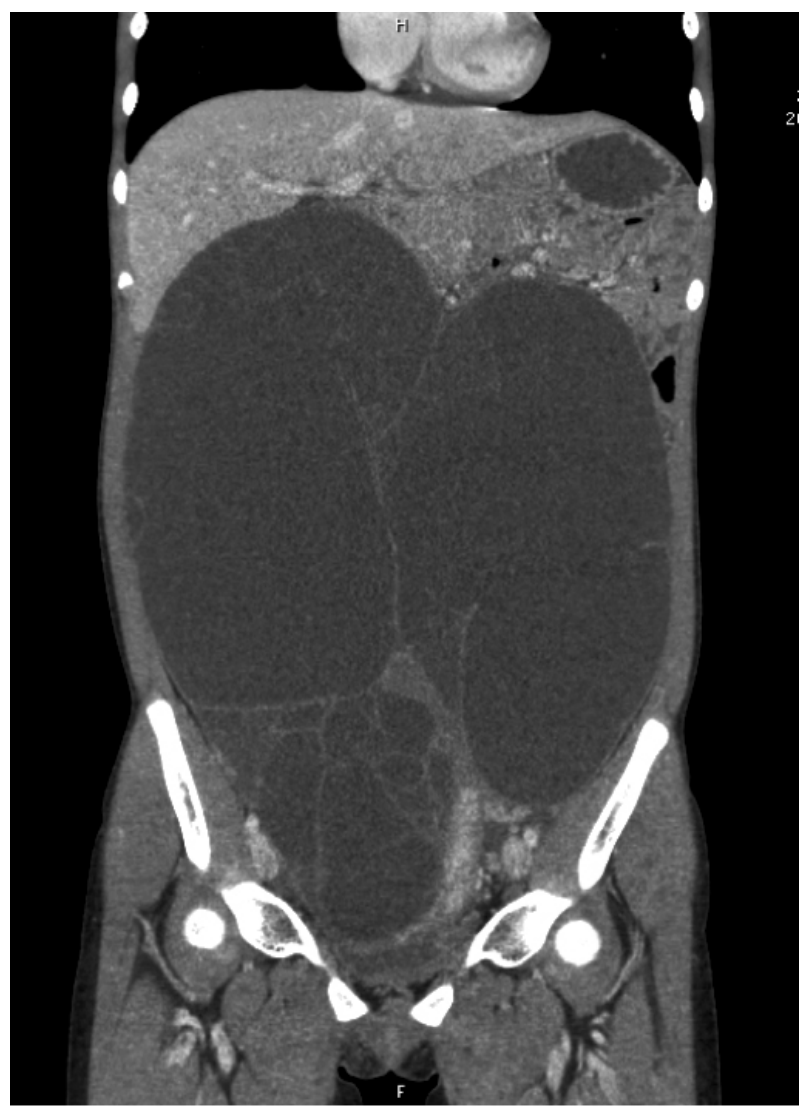

Figure 1. Abdominal contrast-enhanced computed tomography showing a large, multilocular tumor with clear boundaries spreading throughout the whole abdominal cavity from the right upper quadrant to the pelvic cavity.

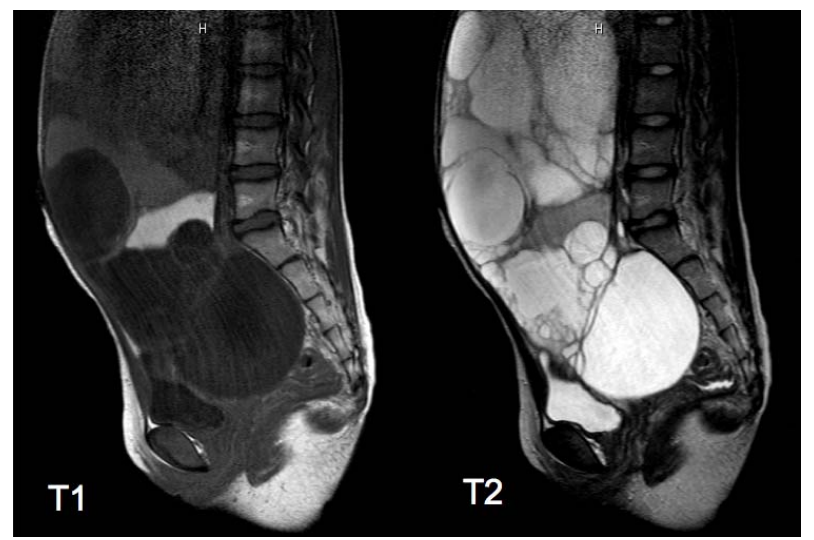

Figure 2. Magnetic resonance imaging of the lesion, showing high intensity on T1-weighted imaging and the low intensity on the T2-weighted imaging.

because the right ovary and bilateral adnexa appeared normal. The tumor measured $26 \times 18 \mathrm{~cm}$ and weighed $5860 \mathrm{~g}$ (Figure 3). Intraoperative frozen section of cystic wall showed mucinous cystadenoma. Microscopic examination after the operation showed multilocular lesions with a papillary structure displaying multiple layers

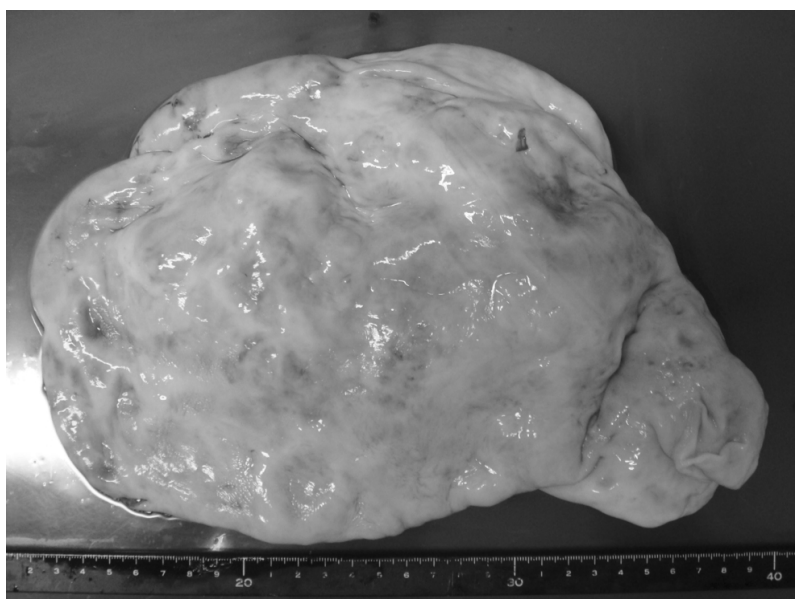

Figure 3. The tumor measuring $26 \times 18 \mathrm{~cm}$ and weighing $5860 \mathrm{~g}$.

of columnar mucus-producing epithelium. Histological diagnosis was mucinous ovarian cystadenoma with borderline malignancy, as cell dysplasia suggestive of carcinoma was not present and no stromal invasion was identified (Figure 4).

Postoperative course was uneventful. Serum CA125 level normalized within 3 months and menarche occurred 5 months later. No evidence of recurrence has been seen as of 2 years postoperatively.

\section{DISCUSSION}

Mucinous ovarian tumor is rare in children, with only 16 cases in premenarchal girls reported to date [3-5,7-15]. These cases are summarized in Table 1. In all cases, age was more than 10 years and signs and symptoms were vague and non-specific. Abdominal pain presented in cases with torsion, but many of the remaining cases only displayed abdominal distension, as in our case. Many patients presented with large tumors, with some as much as $6-7 \mathrm{~kg}$. The extent of tumor enlargement seems attributable to the mildness of the associated abdominal symptoms.

Histological findings included cystadenoma in 9 cases, cystadenocarcinoma in 2 cases, and borderline malignnancy such as in the present patient in 5 cases. Borderline ovarian tumor (BOT), which comprises about $10 \%$ $15 \%$ of all epithelial ovarian malignancies, is characterized pathologically by features of malignant tumors, including cellular proliferation, stratification of the epithelial lining of the papillae, nuclear atypia, and mitotic activity, but without destructive stromal invasion [6]. Those findings were identified in our case, so BOT was diagnosed. In this review of premenarchal mucinous ovarian tumors, all BOT cases were stage I and all patients with BOT or adenoma were alive without recurrence as of final follow-up. 

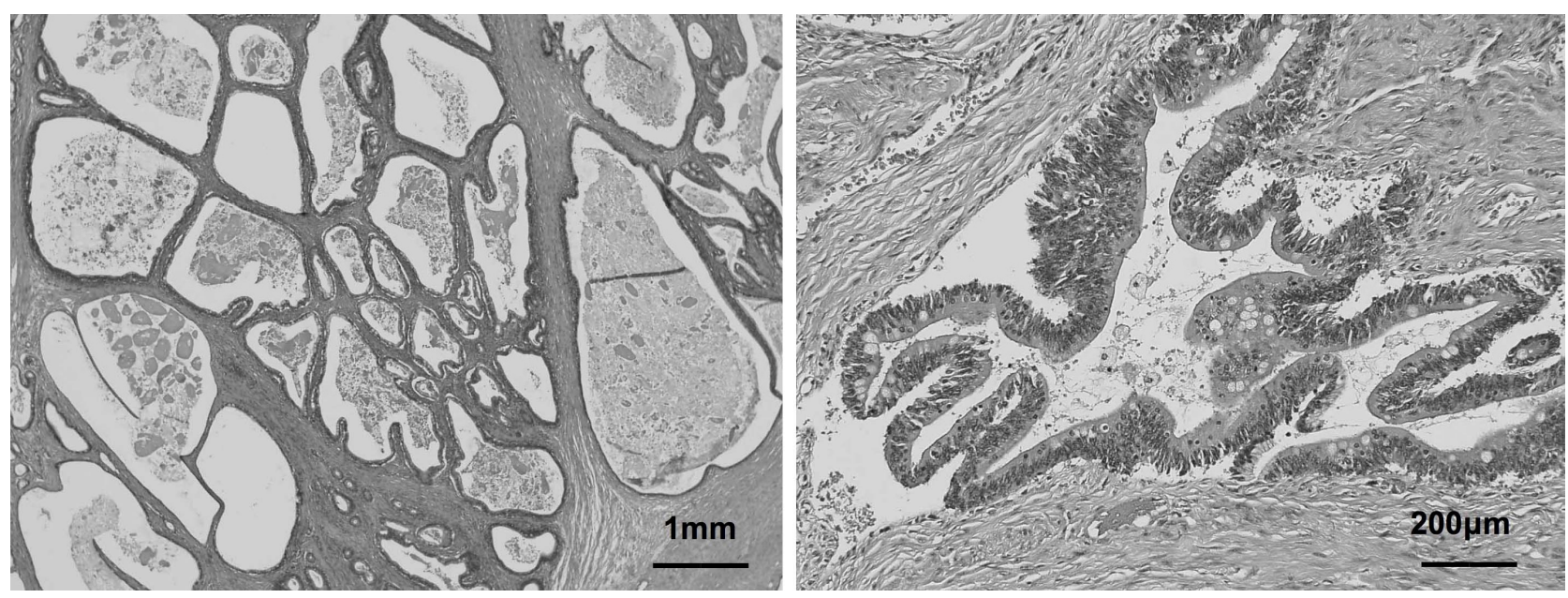

Figure 4. Microscopic examination showing that multilocular lesions with a papillary structure comprising multiple layers of columnar, mucus-producing epithelium.

Table 1. Ovarian mucinous tumors in premenarchal girls.

\begin{tabular}{|c|c|c|c|c|c|c|c|c|}
\hline No & Reference (year) & Age & Symptom & CA125 & Side & Size & Operation & Outcome/follow up \\
\hline 1 & Eur J Pediatr Surg (2002) & $13 \mathrm{y}$ & Intermittent pain & normal & Left & $1800 \mathrm{~g}$ & Salpingo-oophorectomy & $\begin{array}{l}\text { No recurrence/ } \\
1 \text { year after operation }\end{array}$ \\
\hline 2 & $\begin{array}{l}\text { J pediatr Adolesc Gynecol } \\
(2005)\end{array}$ & $13 \mathrm{y}$ & Abdominal distension & elevated & Left & $7000 \mathrm{~g}$ & Salpingo-oophorectomy & $\begin{array}{l}\text { No recurrence/ } \\
2.5 \text { years after operation }\end{array}$ \\
\hline 3 & $\begin{array}{l}\text { Clin Exp Obstet Gynecol } \\
\text { (2006) }\end{array}$ & $11 \mathrm{y}$ & Acute abdomen & normal & Left & $5.5 \mathrm{~cm}$ & Oophorectomy & $\begin{array}{l}\text { No recurrence/ } \\
2 \text { years after operation }\end{array}$ \\
\hline 4 & Pediatr Surg Int (2006) & $13 \mathrm{y}$ & Abdominal pain & normal & Right & $34 \mathrm{~cm}$ & Salpingo-oophorectomy & $\begin{array}{l}\text { No recurrence/ } \\
4 \text { years after operation }\end{array}$ \\
\hline 5 & Pediatr Surg Int (2006) & $14 \mathrm{y}$ & Abdominal distension & normal & Left & $26 \mathrm{~cm}$ & Salpingo-oophorectomy & $\begin{array}{l}\text { No recurrence } / 2.6 \\
\text { years after operation }\end{array}$ \\
\hline 6 & $\begin{array}{l}\text { Eur J Gynecol Oncol } \\
\text { (2006) }\end{array}$ & $13 \mathrm{y}$ & Abdominal distension & normal & Left & $4000 \mathrm{~cm}^{3}$ & Salpingo-oophorectomy & $\begin{array}{l}\text { No recurrence/16.2 } \\
\text { years after operation }\end{array}$ \\
\hline 7 & $\begin{array}{l}\text { Eur J Gynecol Oncol } \\
(2006)\end{array}$ & $13 \mathrm{y}$ & Abdominal pain & elevated & Left & $40 \mathrm{~cm}^{3}$ & Oophorectomy & $\begin{array}{l}\text { No resurrence/3.6 } \\
\text { years after operation }\end{array}$ \\
\hline 8 & $\begin{array}{l}\text { J pediatr Adolesc Gynecol } \\
(2008)\end{array}$ & $14 \mathrm{y}$ & Abdominal distension & normal & Right & $7200 \mathrm{~g}$ & Salpingo-oophorectomy & $\begin{array}{l}\text { No recurrence } / 1 \\
\text { year after operation }\end{array}$ \\
\hline 9 & Scaudi Med J (2008) & $12 \mathrm{y}$ & Abdominal distension & normal & Left & $8000 \mathrm{~g}$ & Salpingo-oophorectomy & $\begin{array}{l}\text { No recurrence } / 9 \\
\text { months after operation }\end{array}$ \\
\hline 10 & Gynecol Oncol (1992) & $12 \mathrm{y}$ & Discomfort & elevated & Left & $630 \mathrm{~g}$ & Salpingo-oophorectomy & $\begin{array}{l}\text { No recurrence/1 } \\
\text { year after operation }\end{array}$ \\
\hline 11 & J Pediatr Surg (2001) & $15 \mathrm{y}$ & Abdominal distension & N.A. & Right & $6800 \mathrm{~g}$ & Salpingo-oophorectomy & $\begin{array}{l}\text { No recurrence } / 3 \\
\text { years after operation }\end{array}$ \\
\hline 12 & $\begin{array}{l}\text { Eur J Gynecol Oncol } \\
(2006)\end{array}$ & $12 \mathrm{y}$ & Abdominal distension & normal & Right & $4100 \mathrm{~cm}^{3}$ & Salpingo-oophorectomy & $\begin{array}{l}\text { No recurrence/ } 1.2 \\
\text { years after operation }\end{array}$ \\
\hline 13 & $\begin{array}{l}\text { J pediatr Adolesc Gynecol } \\
(2010)\end{array}$ & $13 \mathrm{y}$ & Acute abdomen & elevated & Left & $1120 \mathrm{~g}$ & Oophorectomy & $\begin{array}{l}\text { No recurrence } / 8 \\
\text { months after operation }\end{array}$ \\
\hline 14 & Our Case (2012) & $12 \mathrm{y}$ & Abdominal distension & elevated & Left & $5869 \mathrm{~g}$ & Oophorectomy & $\begin{array}{l}\text { No recurrence } / 2 \\
\text { years after operation }\end{array}$ \\
\hline 15 & South Med J (1982) & $10 \mathrm{y}$ & Abdominal pain & N.A. & Left & N.A. & Salpingo-oophorectomy & $\begin{array}{l}\text { No recurrence } / 1.8 \\
\text { years after operation }\end{array}$ \\
\hline 16 & J Pediatr Surg (2001) & $11 \mathrm{y}$ & Discomfort & N.A. & Left & $15 \mathrm{~cm}$ & Salpingo-oophorectomy & $\begin{array}{l}\text { Dead/ } 2 \text { years } \\
\text { after operation }\end{array}$ \\
\hline
\end{tabular}

1 - 9: cystadenoma; 10 - 14: borderline malignancy; 15 - 16: cystadenocarcinoma; N.A.: not available. 
CA125 has been widely used as a marker of ovarian tumors. In the cases we reviewed, CA125 levels were increased in three of four BOT cases measured, but only two of nine cases adenoma cases. Serum CA125 levels in BOT cases, including the present case, tended to be high compared to levels in adenoma cases. CA125 level at initial diagnosis is reportedly associated with prognosis in adult BOT cases [16]. Conversely, CA125 shows a high false-positive rate and poor sensitivity and specificity for epithelial ovarian malignancies, so the real utility of CA125 as a marker of ovarian tumors is unclear $[5,17]$. If the preoperative CA125 level is high as in our case, this value seems useful for identifying recurrent or residual disease [8,15].

Guidelines for surgical treatment of BOT resemble those for ovarian cancer, and include total hysterectomy, bilateral salpingo-oophorectomy and staging procedures in women who do not wish to become pregnant in the future. However, fertility is an important issue for premenarchal children. The role of fertility-sparing surgery has been discussed in adult cases, as the prognosis of BOT is excellent and the lesion tends to arise during the child-bearing years. Some reports have compared the fertility-sparing surgery with radical surgery $[16,18]$. In those studies, the recurrence rate was somewhat higher in the fertility-sparing group than in the radical surgery group. In the fertility-sparing surgery group, the most common pattern of recurrence was isolated recurrence in the remaining ovaries. In these women, recurrence appears amenable to successful salvege with repeated surgery. Cystectomy may have a greater chance of preserveing fertility, but is associated with higher recurrence rates than those seen after oophorectomy. Salpingo-oophorectomy has thus been recommended as fertility-sparing surgery $[3,15,16,18]$. In our case, oophorectomy was performed with a small incision because intraoperative frozen-section histopathological examination indicated mucinous cystadenoma and the contralateral ovary was intact. In this review of premenarchal BOT, all cases underwent salpingo-oophorectomy or oophoretomy, and were alive without recurrence as of the last follow-up. Salpingo-oophorectomy or oophoretomy for premenarchal BOT appears appropriate when the operative findings reveal localized unilateral disease.

\section{REFERENCES}

[1] Brown, M.F., Hebra, A., McGeehin, K. and Ross, A.J. (1993) Ovarian masses in children: A review of 91 cases of malignant and benign masses. Journal of Pediatric Surgery, 28, 930-933. doi:10.1016/0022-3468(93)90700-U

[2] Cass, D.L., Hawkins, E., Brandt, M.L., Chintagumpala, M., Bloss, R.S., Milewicz, A.L., Minifee, P.K., Wesson,
D.E. and Nuchtern, J.G. (2001) Surgery for ovarian masses in infants, children, and adolescents: 102 consecutive patients treated in a 15-year period. Journal of Pediatric Surgery, 36, 693-699. doi:10.1053/jpsu.2001.22939

[3] Sri Paran, T., Mortell, A., Devaney, D., Pinter, A. and Puri, P. (2006) Mucinous cystadenoma of the ovary in perimenarchal girls. Pediatric Surgery International, 22, 224227. doi:10.1007/s00383-005-1624-1

[4] Flotho, C., Rückauer, K., Duffner, U., Bergstässer, E., Böhm, N. and Niemeyer, C.M. (2001) Mucinous cystadenoma of the ovary in a 15-year-old girl. Journal of Pediatric Surgery, 36, 1-3. doi:10.1053/jpsu.2001.24019

[5] Stankovic, Z., Djuricic, S., Djukic, M., Jovanovic, D. and Vasiljevic, M. (2006) Epithelial ovarian tumors and CA125 in premenarchal girls. European Journal of Gynaecological Oncology, 27, 597-599.

[6] Ronnett, B.M., Kajdacsy-Balla, A., Gilks, C.B., Merino, M.J., Silva, E., Werness, B.A. and Young, R.H. (2004) Mucinous borderline ovarian tumors: Points of general agreement and persistent controversies regarding nomenclature, diagnostic criteria, and behavior. Human Pathology, 35, 949-960. doi:10.1016/j.humpath.2004.03.006

[7] Hernandez, E., Rosenshein, N.B. and Parmley, T.H. (1982) Mucinous cystadenocarcinoma in a premenarchal girl. Southern Medical Journal, 75, 1265-1267. doi:10.1097/00007611-198210000-00029

[8] Deprest, J., Moerman, P., Corneillie, P. and Ide, P. (1992) Ovarian borderline mucinous tumor in a premenarchal girl: Review on ovarian epithelial cancer in young girls. Gynecologic Oncology, 45, 219-224. doi:10.1016/0090-8258(92)90290-Y

[9] Shankar, K.R., Wakhlu, A., Kokai, G.K., McDowell, H. and Jones, M.O. (2001) Ovarian adenocarcinoma in premenarchal girls. Journal of Pediatric Surgery, 36, 511555. doi:10.1053/jpsu.2001.21617

[10] Yazici, M., Etensel, B., Gürsoy, H. and Erkuş, M. (2002) Mucinous cystadenoma: A rare abdominal mass in childhood. European Journal of Pediatric Surgery, 12, 330332. doi:10.1055/s-2002-35959

[11] Vizza, E., Galati, G.M., Corrado, G., Atlante, M., Infante, C. and Sbiroli, C. (2005) Voluminous mucinous cystadenoma of the ovary in a 13-year-old girl. Journal of Pediatric and Adolescent Gynecology, 18, 419-422. doi:10.1016/j.jpag.2005.09.009

[12] Grapsa, D., Kairi-Vassilatou, E., Hasiakos, D. and KondiPafiti, A. (2006) Ovarian mucinous cystadenoma with extended calcification in an 11-year-old girl: Case report and review of the literature. Clinical \& Experimental $\mathrm{Ob}$ stetrics \& Gynecology, 33, 181-182.

[13] Alobaid, A.S. (2008) Mucinous cystadenoma of the ovary in a 12-year-old girl. Saudi Medical Journal, 29, 126-128.

[14] Karaman, A., Azili, M.N., Boduroğlu, E.C., Karaman, I., Erdoğan, D., Cavuşoğlu, Y.H., Aslan, M.K. and Cakmak, O. (2008) A huge ovarian mucinous cystadenoma in a 14-year-old premenarchal girl: Review on ovarian mucinous tumor in premenarchal girls. Journal of Pediatric and Adolescent Gynecology, 21, 41-44. 


$$
\text { doi:10.1016/j.jpag.2007.09.005 }
$$

[15] Iwasaki, M., Taira, K., Kobayashi, H. and Saiga, T. (2010) Ovarian mucinous cystadenoma of borderline malignancy in a premenarchal girl. Journal of Pediatric and Adolescent Gynecology, 23, e119-e123. doi:10.1016/j.jpag.2009.09.011

[16] Park, J.Y., Kim, D.Y., Kim, J.H., Kim, Y.M., Kim, Y.T. and Nam, J.H. (2009) Surgical management of borderline ovarian tumors: The role of fertility-sparing surgery. Gy- necologic Oncology, 113, 75-82. doi:10.1016/j.ygyno.2008.12.034

[17] Moss, E.L., Hollingworth, J. and Reynolds, T.M. (2005) The role of CA125 in clinical practice. Journal of Clinical Pathology, 58, 308-312. doi:10.1136/jcp.2004.018077

[18] Tinelli, R., Tinelli, A., Tinelli, F.G., Cicinelli, E. and Malvasi, A. (2006) Conservative surgey for borderline ovarian tumors: A review. Gynecologic Oncology, 100, 185-191. doi:10.1016/j.ygyno.2005.09.02 